\title{
The potential role of human osteoblasts for periprosthetic osteolysis following exposure to wear particles
}

\author{
KATRIN LOCHNER $^{1}$, ANDREAS FRITSCHE ${ }^{1}$, ANIKA JONITZ ${ }^{1}$, DORIS HANSMANN ${ }^{1}$, \\ PETRA MUELLER $^{2}$, BRIGITTE MUELLER-HILKE ${ }^{3}$ and RAINER BADER ${ }^{1}$ \\ ${ }^{1}$ Department of Orthopaedics, ${ }^{2}$ Laboratory of Cell Biology and ${ }^{3}$ Department of Immunology, \\ University of Rostock, D-18057 Rostock, Germany
}

Received June 15, 2011; Accepted July 18, 2011

DOI: $10.3892 / \mathrm{ijmm} .2011 .778$

\begin{abstract}
Aseptic loosening in total hip replacement is mainly caused by wear particles inducing inflammation and osteolysis. Wear can be a consequence of micromotions at the interface between implant and bone cement. Due to complex cellular interactions, different mediators (e.g. cytokines, proteinases) are released, which can promote osteolytic processes in the periprosthetic tissue followed by loosening of the implant. Furthermore, a reduced matrix synthesis and an induced apoptosis rate can be observed. The purpose of this study was to evaluate to what extent human primary osteoblasts exposed to wear particles are involved in the osteolysis. The viability, the secretion of collagen and collagenases and the variety of released cytokines after particle exposure was examined. Therefore, human osteoblasts were incubated with particles experimentally generated in the interface between hip stems with rough and smooth surface finishings as well as different material compositions (Ti-6Al-7Nb, Co-28Cr-6Mo and 316L) and bone cement mantle made of Palacos $\mathrm{R}$ containing zirconium oxide particles. Commercially pure titanium particles, titanium oxide, polymethylmethacrylate and particulate zirconium oxide were used as references. The results revealed distinct effects on the cytokine release of human osteoblasts towards particulate debris. Thereby, human osteoblasts released increased levels of interleukine (IL)- 6 and IL-8 after treatment with metallic wear particles. The expression of VEGF was slightly induced by all particle entities at lower concentrations. Apoptotic rates were enhanced for osteoblasts exposed to all the tested particles. Furthermore, the de novo synthesis of type 1 collagen was reduced and the expression of the matrix metalloproteinase (MMP)-1 was considerably increased. However, wear particles of Co-28Cr-6Mo stems seemed to be more aggressive, whereas particles derived from stainless
\end{abstract}

Correspondence to: Dr Katrin Lochner, Department of Orthopaedics, University of Rostock, Doberaner Str. 142, D-18057 Rostock, Germany E-mail: katrin.lochner@med.uni-rostock.de

Key words: abrasive wear, inflammation, osteolysis, osteoblasts, cytokines, type 1 collagen, apoptosis steel stems caused less adverse cellular reaction. Among the reference particles, which caused less altered reactions in the metabolism of osteoblasts in general, $\mathrm{ZrO}_{2}$ can be assumed as the material with the smallest cell biological effects.

\section{Introduction}

A major problem in orthopaedic surgery is the aseptic loosening of endoprosthetic implants caused by abrasive wear particles (1). In particular at the interface between implant and surrounding bone cement abrasive wear particles can be released which lead to inflammatory reactions and the generation of mediators like cytokines and chemokines (2). The continuous generation and presence of particulate wear debris in the periprosthetic tissue results in a chronic inflammatory state, i.e. macrophages and foreign body giant cells release a variety of cytokines after phagocytosis of different wear particles (3-6). Hence, osteoblastic cells are suppressed, but osteoclastic cells show higher rates of proliferation leading to bone resorption. The consequence is weakening of the adjacent bone stock along with the aseptic loosening of the endoprosthetic implants and the necessity to revision surgery.

Particulate wear debris is known to activate a variety of cellular responses in macrophages, fibroblasts, osteoblasts and osteoclasts (7). These cell types are associated with the development of the periprosthetic osteolysis. Beside enhanced and chronic inflammatory reactions in the periprosthetic region, the cellular recruitment to this region is promoted by induced chemokine expression (8-12). For example, interleukine (IL)-8 and monocyte chemotactic protein (MCP)-1 are potent chemotactic agents that attract macrophages and monocytes. Both chemokines have been identified in the periprosthetic region associated with osteolysis (7). IL-6 affects long term human marrow cultures and forms multinucleated cells with many features of the osteoclast phenotype (13).

The vascular endothelial growth factor (VEGF) is a key regulator of physiological and pathological angiogenesis $(14,15)$. For example, pathological angiogenesis is related to higher vascularisation of inflammatory areas and tumours providing their blood supply. Furthermore, VEGF is an indicator of several inflammatory conditions and also responsible for the migration of monocytes and the proliferation of several types of fibroblasts (16-18). 
While cytokines may affect the bone metabolism negatively by the suppression of osteoblastic cells, collagenases directly destroy bone matrix by degrading different types of collagen. Vidovszky et al (19) compared tissue from osteolytic and non-osteolytic regions of failed cementless total hip replacements and found that the amount of collagenase, gelatinase, and stromelysin [matrix metalloproteinase (MMP)-1, MMP-2 and MMP-11] was elevated in the interfacial membranes from osteolytic regions.

However, it is not only an increased osteoclastic bone resorption due to particle exposure that can disrupt the balance in the bone remodelling process, but also a reduced bone formation caused by a direct negative impact of metallic particles on osteoblasts (20). As many authors already published, the synthesis of collagen type 1 as the major component of bone matrix can be considerably decreased $(21,22)$.

The presented in vitro study is focused on the cellular effects of wear particles derived from the interface between hip stems with rough and smooth surface finishing as well as different material compositions and the surrounding bone cement. While the majority of published studies employed commercial particles and monocytic or osteosarcoma cell lines in in vitro experiments $(2,11,23-25)$, the objective of this study was to evaluate generated wear particles of different implant materials regarding their effect on human, primary osteoblasts. We focused on particles derived from cemented titanium, cobalt chromium and stainless steel stems. After exposure with these wear particles the secretion of different cytokines (IL-6, IL-8, MCP-1 and VEGF) as well as the release of procollagen type 1 and collagen degenerating proteinase MMP-1 from the primary osteoblasts were analysed. Moreover, the influence of the wear particles on the programmed cell death of bone forming cells was examined and compared to commercially available particles. In this context, besides the already known role of osteoblasts for bone formation and integration of implants into bone, their relevance for destruction of bone by influencing the expression of proteinases or osteoclastogenesis will be estimated.

\section{Materials and methods}

Generation and preparation of abrasive wear particles. Particles were generated by simulating the interfacial wear between total hip stems and bone cement. This was achieved by using a special test apparatus (26). For particle generation cemented standard total hip stems made of either a Titanium alloy (Ti-6Al-7Nb), a Cobalt-Chromium alloy (Co-28Cr-6Mo) or stainless steel (316L) were employed. All stems were geometrically identical and characterised by a defined surface roughness (Rz value). A smooth surface finishing with a Rz value of approximately $7 \mu \mathrm{m}$, and a rough surface finishing with $20 \mu \mathrm{m}$ were used. The cement mantle was manufactured from commercially available polymethylmethacrylate (PMMA) bone cement (Palacos ${ }^{\circledR} \mathrm{R}$, Heraeus Kulzer, Wehrheim, Germany), containing $15 \%$ zirconium oxide $\left(\mathrm{ZrO}_{2}\right)$ particles as radio-opaque additive.

The collected wear debris, i.e. a conglomerate of metallic and bone cement particles, was used for cell biological investigations. Thereby, the amount of Ti-6Al-7Nb, Co-28Cr-6Mo and bone cement particles was previously described by Lenz et al (27). Moreover, commercially pure titanium powder with an average particle size of $3 \mu \mathrm{m}$ (cp-Ti; Grade E, dry; Chemetall, Frankfurt, Germany), pure polycrystalline $\mathrm{ZrO}_{2}$ particles with mean size of $1.75 \mu \mathrm{m}$ (Selectipur, Heraeus Kulzer) as well as particles out of PMMA (Heraeus Kulzer) and titanium oxide $\left(\mathrm{TiO}_{2}\right)$ with a mean size of $1.8 \mu \mathrm{m}(\mathrm{BioCer}$ $\mathrm{GmbH}$, Bayreuth, Germany) were also used.

Five milligrams of each generated wear particles and commercially available reference particles were sterilized by the use of gamma radiation. Subsequently, a stock solution $(10 \mathrm{mg} / \mathrm{ml})$ was prepared by suspending the particles in $0.5 \mathrm{ml}$ sterile PBS (PAA, Coelbe, Germany). Further dilutions with cell culture medium created the final particle concentrations of 0.1 and $0.01 \mathrm{mg} / \mathrm{ml}$.

Isolation and cultivation of human primary osteoblasts. Human primary osteoblasts were isolated under sterile conditions from bone marrow derived from femoral heads of patients undergoing primary total hip replacement. All samples were collected after participants signed written informed consent forms and approval by the Local Ethics Committee (AZ: 2010-10).

Spongiosa specimens were extracted from the femoral heads, suspended in sterile phosphate-buffered saline (PBS) and washed twice. Osteoblasts were obtained from the resulting material by enzymatic digestion with collagenase $\mathrm{A}$ and dispase II (both from Roche, Prenzberg, Germany) in Dulbecco's modified Eagle's medium (DMEM, Biochrome AG, Berlin, Germany) supplemented with $1 \%$ penicillin/streptomycin as well as $1 \%$ amphotericin B (both from Gibco ${ }^{\circledR}$-Invitrogen Cell Culture Products, Paisley, UK) for $3 \mathrm{~h}$ at $37^{\circ} \mathrm{C}, 5 \% \mathrm{CO}_{2}$ and constant shaking. The resulting preparation was filtered through a cell strainer (70 $\mu \mathrm{m}$ pore size; BD Biosciences, Bedford, UK), centrifuged at $900 \mathrm{rpm}$ for $10 \mathrm{~min}$ and the pellet was resuspended in complete medium. The complete medium was supplemented with $10 \%$ fetal calf serum (Gibco ${ }^{\circledR}$-Invitrogen Cell Culture Products), $1 \%$ penicillin and streptomycin, $1 \%$ amphotericin B, $50 \mu \mathrm{g} / \mathrm{ml}$ L-ascorbate-2-phosphate, $10 \mathrm{mM}$ $\beta$-glycerophosphate and $100 \mathrm{mM}$ dexamethasone (SigmaAldrich, Munich, Germany).

Freshly isolated osteoblast-like cells were plated in $25 \mathrm{~cm}^{2}$ culture flasks in $8 \mathrm{ml}$ complete medium and incubated at $37^{\circ} \mathrm{C}$ in a humidified atmosphere of $5 \% \mathrm{CO}_{2}$ and $95 \%$ air. The culture medium was changed every two days in the course of which non-adherent cells were aspirated. The progress of proliferation was determined by a microscopic control. After a confluency of $90 \%$ the cells were split in a 1:6 ratio. The cultivated cells were used in experiments at passage three. To verify the osteogenic character of isolated cells, alkaline phosphatase stainings were carried out.

For in vitro experiments, the osteoblasts were transferred to 96-well plates with 3,000 cells/well and $200 \mu \mathrm{l}$ complete medium. The human osteoblasts were allowed to adhere for $24 \mathrm{~h}$ and then the particle-free medium was replaced by the respective particle-containing medium for 48 or $96 \mathrm{~h}$, respectively. Osteoblasts incubated with normal culture medium served as test controls.

For the phenotypical characterisation of the bone cells the de novo synthesis of collagen type 1 was determined by means of ELISA tests. Furthermore, the effects on the apoptosis rate were investigated. Supernatants of osteoblasts incubated with particle-containing medium were investigated for the expression 
of the cytokines IL-6, IL-8, MCP-1 and VEGF and the synthesis of the MMP-1. These data are intended to assess whether osteoblasts being bone forming cells contribute with their induction of osteoclast differentiation and matrix resorption to osteolysis after contact with abrasive wear particles.

Determination of the protein content. Total protein content in the monolayer was measured spectrophotometrically using the commercially available Roti $^{\circledR}$-Quant universal kit (Carl Roth, Karlsruhe, Germany) following manufacturer's instructions. Cells were treated with lysis buffer $(1 \% \mathrm{v} / \mathrm{v}$ Tween, $100 \mathrm{mM}$ PMSF), incubated for $10 \mathrm{~min}$ at room temperature and the lysates of 4-fold preparations combined in $1.5 \mathrm{ml}$ reaction tubes. After centrifugation for $5 \mathrm{~min}$ at 13,000 rpm $50 \mu \mathrm{l}$ of the supernatants were measured in triplicates in a 96-well plate. Each aliquot was mixed with $100 \mu 1$ working solution (15 parts reagent 1 and one part reagent 2 ) and incubated for $30 \mathrm{~min}$ at $37^{\circ} \mathrm{C}$. Finally, light absorbance was measured at $490 \mathrm{~nm}$ on a spectrophotometer (Dynex Technology, Denkendorf, Germany). The total protein concentration was determined from a standard curve of absorbance vs. known protein concentrations [bovine serum albumin fraction $\mathrm{V}$ (Sigma-Aldrich)] run in parallel with experimental samples.

Determination of the apoptosis rate. The cleavage of cytoplasmic histone-associated DNA is characteristic for apoptotic cells. Therefore, the enrichment of mono- and oligonucleosomes in the cytoplasm of apoptotic cells was used as quantification of osteoblast apoptosis $48 \mathrm{~h}$ after exposure to the wear particles. In order to determine the histone-associated DNA fragments the commercially available Cell Death Detection ELISA ${ }^{\text {PLUs }}$ kit (Roche, Mannheim, Germany) was used following manufacturer's instructions. Before the analysis, cells were lysed for $30 \mathrm{~min}$ at room temperature. The cell lysates were centrifuged for $10 \mathrm{~min}$ at $200 \mathrm{x} \mathrm{g}$ and the supernatants were transferred into the streptavidin-coated microtiter plate for analysis. After adding $80 \mu \mathrm{l}$ immunoreagent the assay was incubated for $2 \mathrm{~h}$ at room temperature. This was followed by rinsing each well three times with incubation buffer, pipetting of horseradish peroxidase substrate (ABTS) to the wells and incubating until colour development for 10-20 min. After adding $100 \mu \mathrm{l}$ ABTS Stop Solution the light absorbance was measured at $405 \mathrm{~nm}$ (reference wave length $490 \mathrm{~nm}$ ). The apoptosis rate was then normalised to the control treated group at each time point.

Characterisation of the de novo collagen type 1 synthesis. Type 1 collagen is the most abundant collagen in the bone, which is synthesised as a much larger procollagen precursor molecule and activated by enzymatic cleavage into the smaller collagen molecule. The sequence of the amino acids removed from the carboxyterminal end of the procollagen molecule is known as the carboxyterminal propeptide of procollagen type 1 (CICP). The determined level of procollagen 1 in the cell culture medium reflects the type 1 collagen de novo synthesis and is a useful marker for the metabolic activity of bone cells. The quantitative analysis of the carboxy-terminal propeptide (CICP) in culture supernatants was performed with a commercial immunoassay using monoclonal CICPantibodies (Metra ${ }^{\mathrm{TM}}$ CICP EIA kit, Quidel, Buende, Germany). Medium was collected after 48 and $96 \mathrm{~h}$ of incubation and analysed following the manufacturer's instructions. Shortly, sample supernatant was diluted in a 1:12 ratio, filled in rabbit anti-CICP-coated wells of a 96-well plate and incubated for $45 \mathrm{~min}$ at room temperature. After rinsing each well three times with incubation buffer, a goat anti-rabbit alkaline phosphatase conjugate was added for another $45 \mathrm{~min}$. This was followed by a final incubation period of $30 \mathrm{~min}$ with a working substrate solution and measurement of the light absorbance at $405 \mathrm{~nm}$. The actual concentration of CICP is determined from a standard curve.

Expression of MMP-1. MMPs are zinc-depended endopeptidases with MMP-1 as a triple-helical collagen type 1 degrading enzyme. The quantitative analysis of the MMP-1 content in cell culture supernatants was performed with a commercially available enzyme-linked immunoassay according to the manufacturer's instructions (RayBio ${ }^{\circledR}$ human MMP-1 ELISA kit, RayBio, Norcross, USA). This assay employs an antibody specific for human MMP-1 coated on a 96-well plate. Standards and samples were pipetted into the wells and MMP-1 present in a sample was bound to the wells by the immobilised antibody. The wells were washed and biotinylated anti-human MMP-1 antibody was added. Subsequently, the unbound biotinylated antibody was washed away and HRP-conjugated streptavidin was added to the wells. The wells were again washed, a TMB substrate solution was added to the wells and colour was developed in proportion to the amount of bound MMP-1. The stop solution changed the colour from blue to yellow and the intensity of the colour was measured at $450 \mathrm{~nm}$. The actual concentration of MMP-1 was determined from a standard curve.

Characterisation of inflammatory signals. To investigate the immunstimulatory effect of osteoblasts incubated with abrasive wear particles, the cytokines IL-6, IL-8, MCP-1 and VEGF were quantified in the cell culture supernatant after 48 and $96 \mathrm{~h}$ of incubation using the Multiplex Cytokine assay (Bio-Plex Pro Human Cytokines Group I 5-Plex; Bio-Rad, Munich, Germany). The assay is based on simultaneous multi-cytokine detection in a single well of a 96-well microplate involving fluorochrome-labeled microsphere beads. For the assay osteoblast supernatants, standard solutions and blanks are filled in the corresponding wells of a 96-well filter plate already containing anti-cytokine conjugated beads. After an incubation time of $1 \mathrm{~h}$ and several washing steps the secondary antibody was added for $30 \mathrm{~min}$. Subsequently, streptavidin-phycoerythrin was added to the reaction mixture in order to bind to the biotinylated sites of the secondary antibodies. Finally, the beads were resuspended in assay buffer and detected by the Bio-Plex 200 System using the Bio-Plex Manager software 4.1.1 (both, Bio-Rad).

Cytokine concentrations were calculated using a standard curve derived from a recombinant cytokine standard supported by the Bio-Plex assay.

Flow cytometry. Flow cytometry was performed on primary human osteoblasts from two donors in passage three to exclude the presence of monocytes and macrophages in the cell culture. All steps of the following procedure were performed on ice. After harvesting the cells and preparing a single cell suspension $\left(10^{5}\right.$ cells/500 $\mu$ l PBS supplemented with 

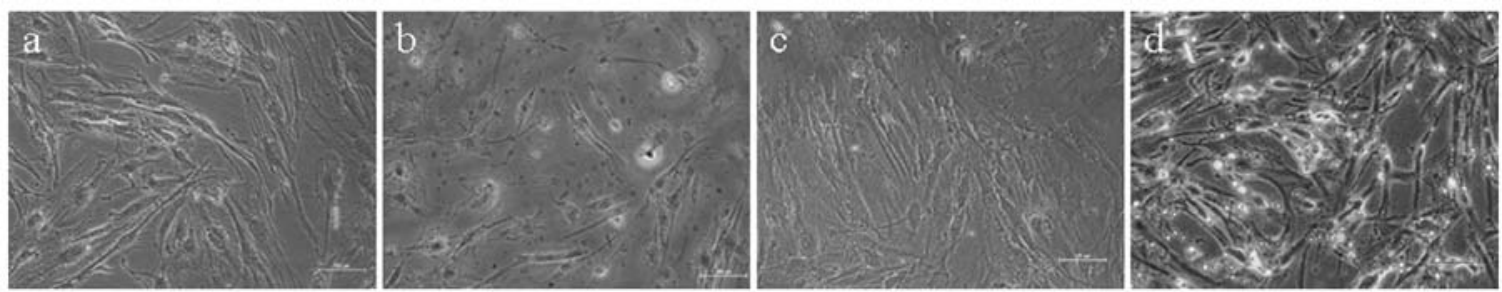

Figure 1. In vitro culture of human, primary osteoblastic cells after (a and b) 48 and (c and d) $96 \mathrm{~h}$ of incubation following treatment with $0.01 \mathrm{mg} / \mathrm{ml}$ particles from rough Ti-6Al-7Nb stem ( $b$ and d). Pictures were taken with a Nikon Eclipse TS100 microscope and a Nikon Digital Sight DS-2Mv camera.

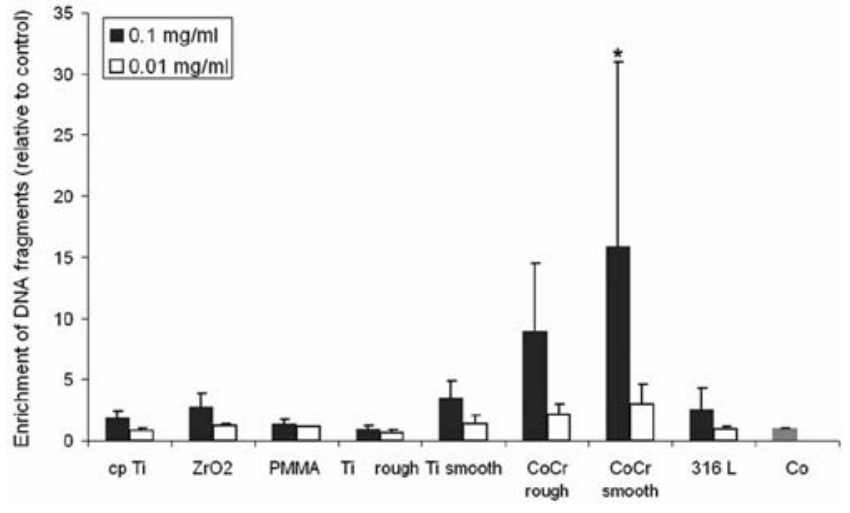

Figure 2. Quantification of osteoblast apoptosis $48 \mathrm{~h}$ after exposure to wear particles of different concentrations by analysing the enrichment of DNA fragments in the cytoplasm of osteoblasts compared to cp $\mathrm{Ti}, \mathrm{ZrO}_{2}$ and PMMA particles and a particle-free control $(n=3)$. Values are means \pm SD.

$1 \%$ bovine serum albumin [BSA (Sigma-Aldrich)], the cells were stained in the dark for $30 \mathrm{~min}$ with fluorescein isothiocyanate (FITC)-conjugated anti-CD68 (monoclonal antibody to human $\mathrm{CD} 68$, Acris Antibodies $\mathrm{GmbH}$ ), phycoerythrin (PE)-conjugated anti-CD14 (monoclonal antibody to human CD14, eBioscience, San Diego, USA) and with mouse isotype (negative control, mouse IgG1-negative control-FITC, Acris Antibodies $\mathrm{GmbH}$ ). The cells were then washed three times with PBS supplemented with $1 \%$ BSA and cell pellets were resuspended in $400 \mu \mathrm{l}$ PBS supplemented with $1 \%$ BSA. Data were collected immediately after antibody-staining on a FACS Calibur cytometer (Becton-Dickinson, Franklin Lakes, NJ). Data analysis was performed with the CellQuest software (Becton-Dickinson).

Statistical analysis. For graphical representation the mean values \pm standard deviation were presented. For all analysis human osteoblast cultures from three independent donors were used. The data of the different cell culture experiments were compared and statistical significances between groups were calculated with one-way ANOVA (post hoc LSD) using SPSS 15.0 for Windows (SPSS, Inc., Chicago). Significance was based on the untreated control at $48 \mathrm{~h}\left({ }^{*} \mathrm{P}<0.05,{ }^{* *} \mathrm{P}<0.01\right.$ and $\left.{ }^{* * * *} \mathrm{P}<0.001\right)$.

\section{Results}

Cell viability. All different particle types affected the cell viability of human osteoblasts in a dose-dependent manner. The mean optical densities (using the MTT assay) obtained in former studies (27) were comparable for all treatment groups.
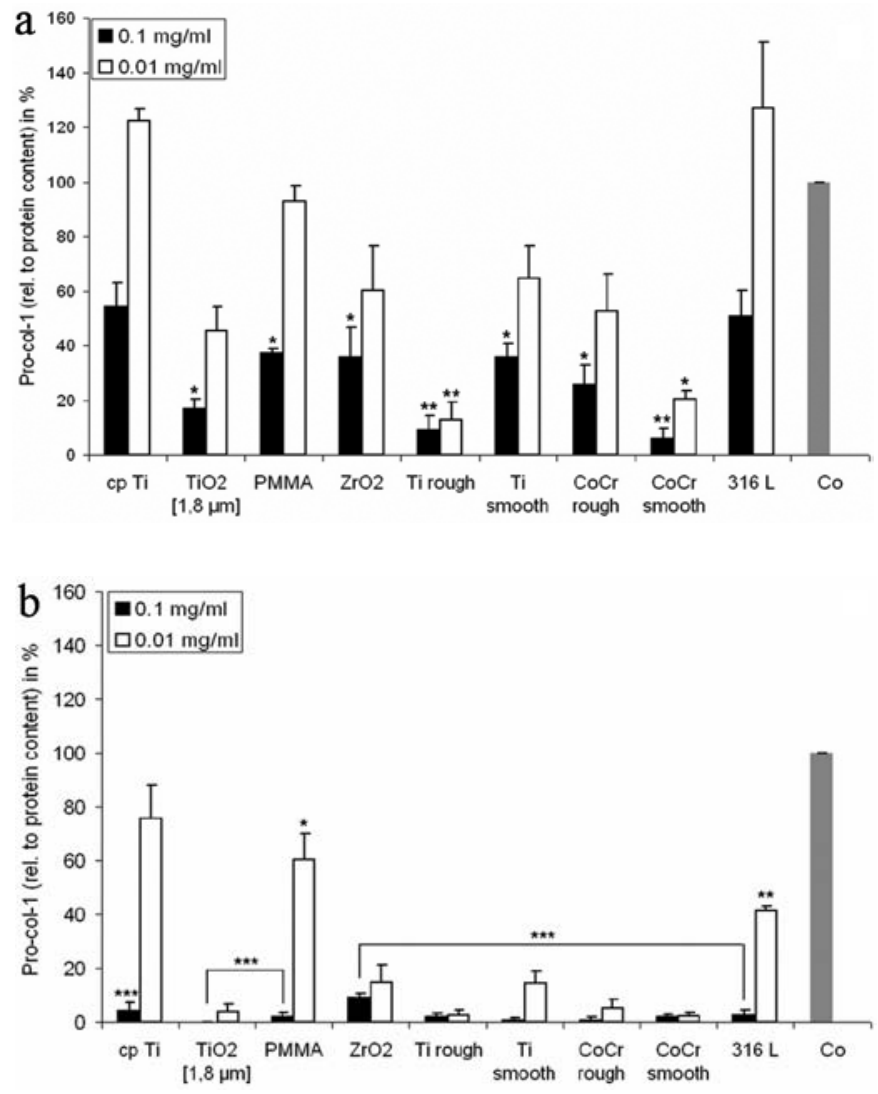

Figure 3. Changes in the procollagen 1 content in human osteoblasts $(n=3)$ after exposure to wear particles of different concentrations after (a) 48 and (b) $96 \mathrm{~h}$. The procollagen 1 amount is displayed relative to the protein content and related to the respective control (in \%). Values are means \pm SD.

Slight decreases of cell viability occurred after incubation with abrasive wear particles at a lower concentration $(0.01 \mathrm{mg} / \mathrm{ml})$ but a distinct decrease after the incubation with higher concentrated particle suspensions $(0.1$ and $1.0 \mathrm{mg} / \mathrm{ml})$ was observed. Analysing the enrichment of mono- and oligonucleosomes in the cytoplasm of osteoblasts was used as quantification of osteoblast apoptosis $48 \mathrm{~h}$ after exposure to the wear particles. Though the amount of DNA fragments in osteoblasts incubated with lower particle concentrations $(0.01 \mathrm{mg} / \mathrm{ml})$ remained almost constant, more DNA fragments were detected in osteoblasts incubated with higher particle concentrations $(0.1 \mathrm{mg} / \mathrm{ml})$ compared to the control group (Fig. 2). An exceptionally negative effect of $\mathrm{CoCr}$ containing particles on osteoblasts was already found at lower concentrations. In contrast, particles from Ti-6Al-7Nb stems as well as commercial cp-Ti and PMMA applied in higher 


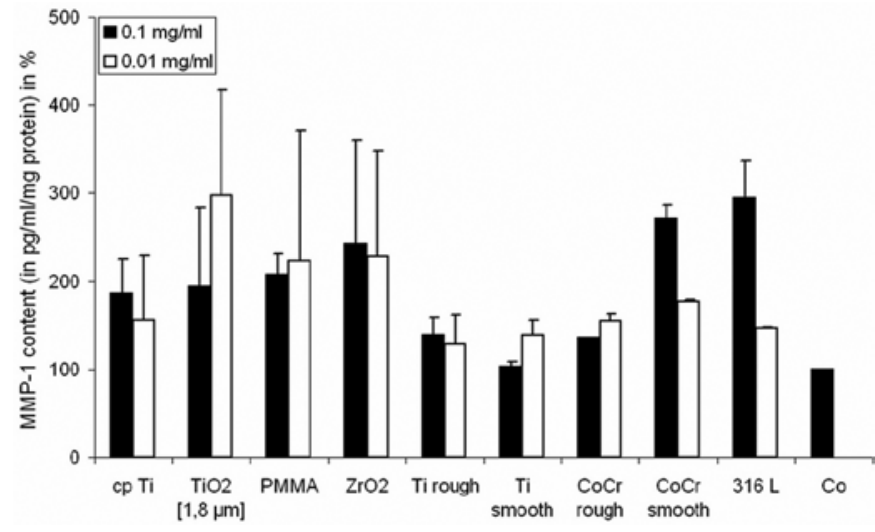

Figure 4. Changes in the MMP-1 content in human osteoblasts $(n=2)$ after exposure to wear particles of different concentrations after $48 \mathrm{~h}$. The MMP-1 amount is displayed relative to the protein content and related to the $48 \mathrm{~h}$ control (in \%). Values are means \pm SD.

concentrations did not lead to an increase of DNA fragments. This reveals that the decreased cell viability analysed with the MTT assay results from the apoptosis of the affected osteoblasts whereas necrosis could not be detected.

Synthesis of collagen type 1. The de novo synthesis of collagen type 1 in osteoblasts was considerably inhibited after particle treatment. Metallic particles in the lower concentration $(0.01 \mathrm{mg} / \mathrm{ml})$ negatively affect the procollagen synthesis. This decrease was measured after $48 \mathrm{~h}$ of incubation and amplified after $96 \mathrm{~h}$ (Fig. 3). Only particles from the stainless steel stem and commercial PMMA powder at the lower concentrations had a negligible effect on the extracellular matrix protein production.

Higher particle concentration led to stronger inhibition of collagen synthesis. After $48 \mathrm{~h}$ (Fig. 3a) the amount of procollagen was decreased by $50 \%$ on average, after $96 \mathrm{~h}$ even more (Fig. 3b). Particles from rough titanium stems and cobalt chromium stems inhibited the release of procollagen type 1 stronger than the other particle types. After four days of particle incubation the production of the extracellular matrix protein collagen type 1 was nearly disconnected.

Matrix metalloproteinase 1 expression. MMP-1 is a zincdependent protease that degrades triple-helical type 1 collagen. After $48 \mathrm{~h}$ particle treatment the expression of MMP-1 in osteoblastic cells was elevated, which was already detectable at the lower concentration levels for all particle groups. Thereby, the highest increase of MMP-1 expression was found after exposure to $\mathrm{ZrO}_{2}$, PMMA and $\mathrm{TiO}_{2}$ reference particles (Fig. 4). Titanium containing stem materials only caused a minor increase of expression. Moreover, a higher particle concentration did not lead to a higher extension of MMP-1 generation (except smooth Co-28Cr-6Mo and 316L).

Interleukin-6. IL-6 is a marker for chronic inflammatory processes and is suspected to induce osteoclast generation. Osteoblasts cultured with different particle types released a higher amount of IL-6 compared to the non-stimulated control cells. This increase of IL-6 expression was already observed at the lowest particle concentration $(0.01 \mathrm{mg} / \mathrm{ml})$ after $48 \mathrm{~h}$

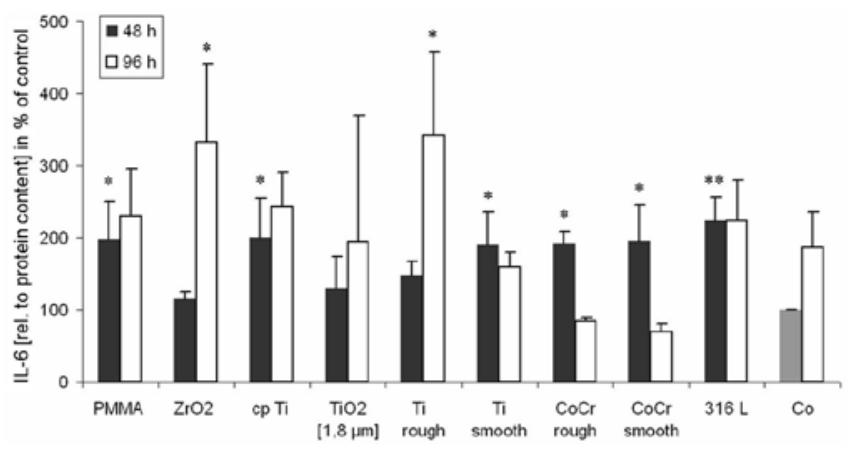

Figure 5. Changes in the IL-6 content in human osteoblasts $(n=3)$ after exposure to wear particles $(0.1 \mathrm{mg} / \mathrm{ml})$ for 48 or $96 \mathrm{~h}$. The IL-6 amount is displayed relative to the protein content and related to the $48 \mathrm{~h}$ control (in \%). Values are means \pm SD.

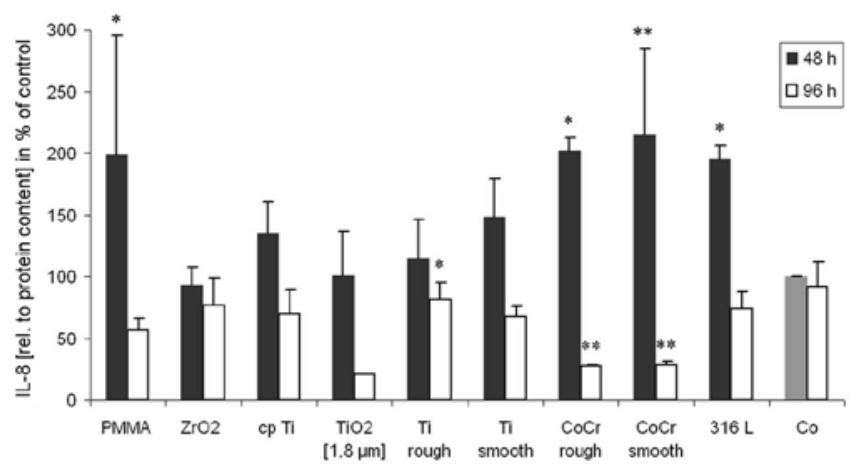

Figure 6. Changes in the IL- 8 content in human osteoblasts $(n=3)$ after exposure to wear particles $(0.1 \mathrm{mg} / \mathrm{ml})$ for 48 or $96 \mathrm{~h}$. The IL- 8 amount is displayed relative to the protein content and related to the $48 \mathrm{~h}$ control (in \%). Values are means \pm SD.

of incubation. In particular, particles from the $\mathrm{Co}-28 \mathrm{Cr}-6 \mathrm{Mo}$ stems and smooth $\mathrm{Ti}-6 \mathrm{Al}-7 \mathrm{Nb}$ stems increased the production of IL-6. Additionally, $\mathrm{TiO}_{2}$ and cp Ti reference particles act as a stimulant for the IL-6 expression. The average expression was between 50 and $100 \%$ percent above the control group (data not shown) and increased further with higher particle concentrations (0.1 mg/ml) (Fig. 5). A longer incubation time (96 h) caused higher IL-6 levels in particle-treated as well as nonstimulated osteoblast cultures (Fig. 5). There was a tendency for cells incubated with either particles from hip stems or reference particles to release more IL-6 than untreated cells, but the differences in the expression levels were not as obvious as after $48 \mathrm{~h}$ of incubation. However, particles from the $316 \mathrm{~L}$ and the Ti-6Al-7Nb stems had a major impact. In contrast, osteoblasts treated with particles from the Co-28Cr-6Mo stems in the higher concentration showed considerably decreased IL-6 levels after $96 \mathrm{~h}$ of incubation (Fig. 5). This may result from lower cell amounts caused by higher apoptotic rates in these samples.

Interleukin-8. Human primary osteoblasts express IL-8 which is among others responsible for osteoclast migration. After $48 \mathrm{~h}$ the IL- 8 levels were only elevated in cultures treated with $0.01 \mathrm{mg} / \mathrm{ml} \mathrm{TiO}_{2}$ and PMMA reference particles as well as particles from the Co-28Cr-6Mo stems (data not shown). The 

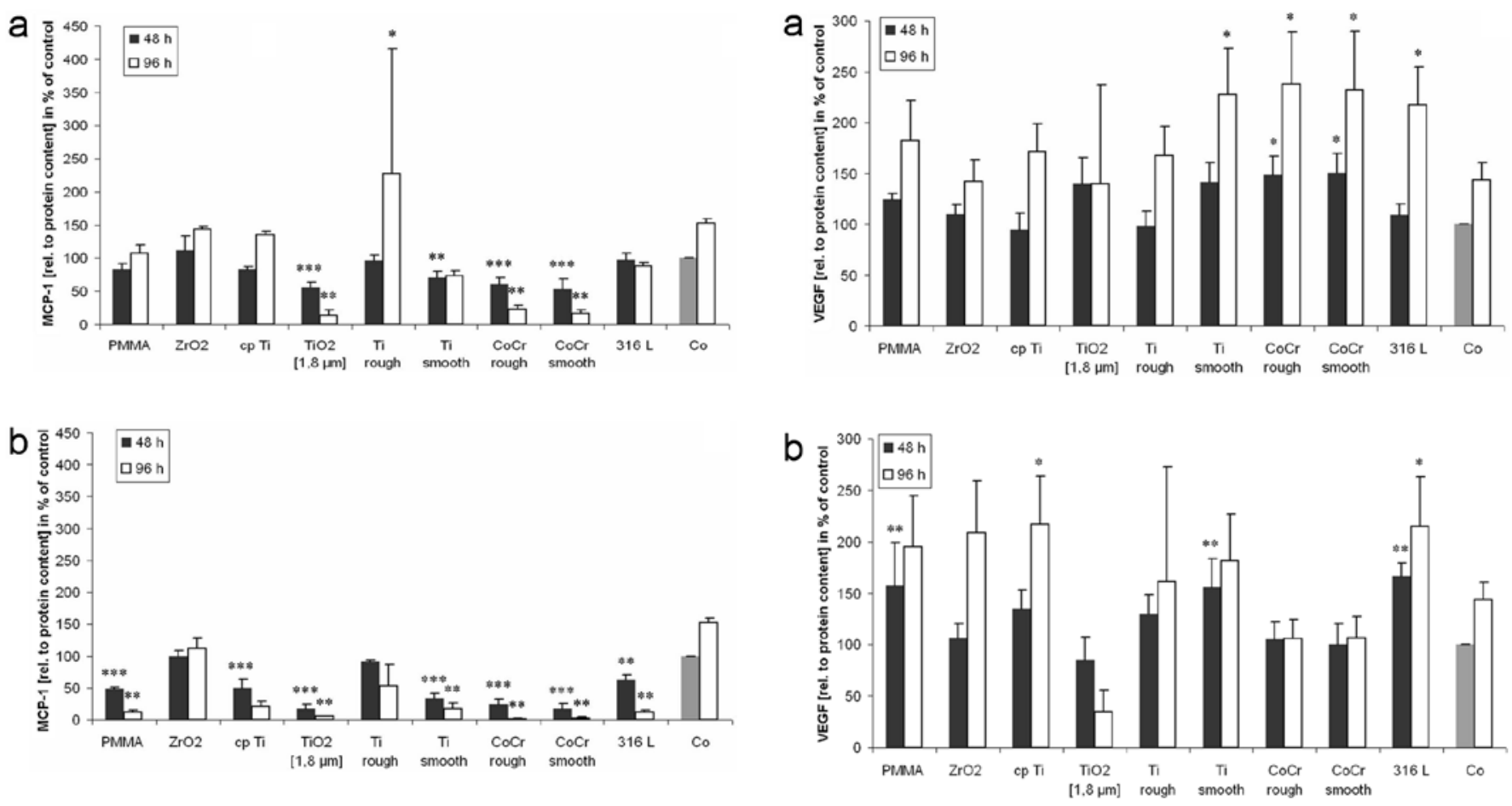

Figure 7. Changes in the MCP-1 content in human osteoblasts $(n=3)$ after exposure to wear particles of different concentrations after 48 or $96 \mathrm{~h}$. (a) $0.01 \mathrm{mg} / \mathrm{ml}$, (b) $0.1 \mathrm{mg} / \mathrm{ml}$. The MCP-1 amount is displayed relative to the protein content and related to the $48 \mathrm{~h}$ control (in \%). Values are means \pm SD

other materials caused no variations above the control values at this concentration whereas higher concentrations $(0.1 \mathrm{mg} / \mathrm{ml})$ led to higher cytokine expression (Fig. 6).

The initial elevated expression of cytokine IL- 8 inverted to a decreased expression after longer incubation. This is significant for $\mathrm{TiO}_{2}$ reference particles as well as particles from both $\mathrm{Co}-28 \mathrm{Cr}-6 \mathrm{Mo}$ and rough $\mathrm{Ti}-6 \mathrm{Al}-7 \mathrm{Nb}$ stems. After $96 \mathrm{~h}$ in non-stimulated osteoblasts no differences of IL-8 levels were found compared to the earlier time point. However, the IL-8 levels were decreased for particle treatment at longer incubation periods, which was observed for all materials and was more pronounced after exposure to the higher particle concentration. Especially particles from the $\mathrm{Co}-28 \mathrm{Cr}-6 \mathrm{Mo}$ stems influenced the IL-8 secretion of osteoblasts (Fig. 6).

Monocyte chemotactic protein-1. MCP-1 as a further marker for osteoclast differentiation was slightly reduced after $48 \mathrm{~h}$ of incubation with different particle types at a concentration of $0.01 \mathrm{mg} / \mathrm{ml}$ (Fig. 7a). A higher particle concentration $(0.1 \mathrm{mg} / \mathrm{ml})$ caused a higher decrease in MCP-1 expression. Particles from the $\mathrm{Co}-28 \mathrm{Cr}-6 \mathrm{Mo}$ stems seemed to be more aggressive. $\mathrm{TiO}_{2}$, cp Ti and PMMA reference particles also showed an inhibitory effect on the MCP-1 expression (Fig. 7b).

After $96 \mathrm{~h}$ the MCP-1 level in non-stimulated cultures was higher compared to the levels after $48 \mathrm{~h}$. The reference materials at $0.01 \mathrm{mg} / \mathrm{ml}$ led to a reduction in MCP-1 expression relative to non-stimulated cultures although the amount of the cytokine was on average higher than after $48 \mathrm{~h}$. Incubation with $0.1 \mathrm{mg} / \mathrm{ml}$ particles inhibited the secretion of MCP-1 considerably. The stem materials at $0.01 \mathrm{mg} / \mathrm{ml}$ led to a reduction of the MCP-1 expression relative to non-stimulated cultures,
Figure 8. Changes in the VEGF content in human osteoblasts $(n=3)$ after exposure to wear particles of different concentrations after 48 or $96 \mathrm{~h}$. (a) $0.01 \mathrm{mg} / \mathrm{ml}$, (b) $0.1 \mathrm{mg} / \mathrm{ml}$. The VEGF amount is displayed relative to the protein content and related to the $48 \mathrm{~h}$ control (in \%). Values are means $\pm \mathrm{SD}$.

while the amount of the cytokine was not altered compared to the earlier time point (Fig. 7a). However, exceptions were the Co-28Cr-6Mo stem-derived particles. They caused a further decrease of the MCP-1 secretion at both concentration points.

Vascular endothelial growth factor. VEGF is a signal protein that can stimulate the growth of new blood vessels as well as the migration of monocytes or macrophages. After $48 \mathrm{~h}$ osteoblasts expressed VEGF. The release of this cytokine was considerably stimulated by treatment with the lower concentration $(0.01 \mathrm{mg} / \mathrm{ml})$ of both $\mathrm{Co}-28 \mathrm{Cr}-6 \mathrm{Mo}$ stems, the smooth Ti-6Al-7Nb and the 316L stem. After $96 \mathrm{~h}$ VEGF was further enriched in the particle and reference group (Fig. 8a). Equally to the above mentioned cytokines, particles from the Co-28Cr-6Mo stems at the higher concentration $(0.1 \mathrm{mg} / \mathrm{ml})$ (Fig. 8b) led to a more reduced VEGF expression.

Flow cytometry. Flow cytometry was performed representatively in samples of two donors. In primary cell cultures no CD68-positive cells (selective for monocytes) were detected, whereas CD14 (selective for monocytes and macrophages) was expressed in $2.43 \%$ and respectively $2.37 \%$ cells of the culture. These results confirmed that the findings can be ascribed to human primary osteoblasts (Fig. 9).

\section{Discussion}

There are many studies concerning the pathogenesis of aseptic implant loosening after total joint arthroplasty (28-30). Abrasive wear is presumed to play a key role for early implant loosening. In this context phagocytosis of wear particles leads 

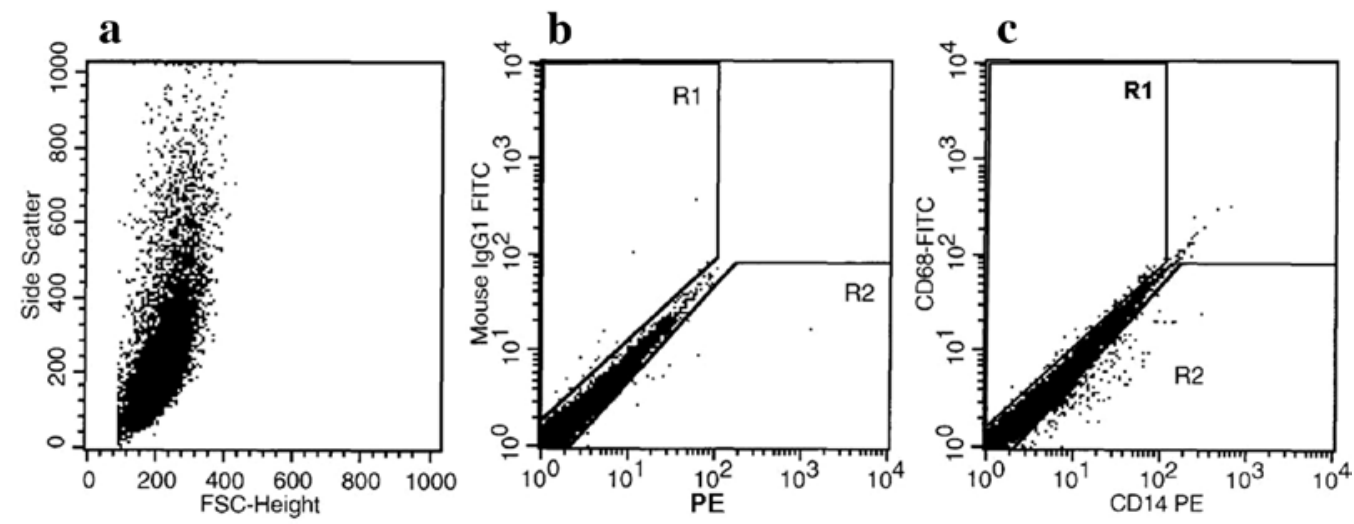

Figure 9. Fluorescence-activated cell sorting (FACS) of CD14 and CD68 expression in primary human osteoblast culture. (a) Side and forward scatter of unlabeled cells, (b) negative control and (c) representative example of primary human osteoblast culture.

to inflammatory reactions, osteolysis and tumour-like granulomatous tissue $(28,31)$. The majority of in vitro cell studies have dealt with commercial particles and monocytic or osteosarcoma cell lines $(2,11,23-25)$. In contrast, the present study focused on particles generated experimentally in a specific test apparatus simulating the micromotion between hip stem and cement mantle (26). Different abrasive wear particles were used for the investigations with human primary osteoblast-like cells.

Osteoblasts are extracellular matrix-producing cells and responsible for bone formation. Analyzing the synthesis of type 1 collagen, the degenerating enzyme MMP-1 and the apoptosis rate, the role of osteoblasts for matrix degeneration was examined. Furthermore, with the expression of the cytokines IL-6, IL-8, MCP-1 and VEGF the inflammatory impact of osteoblasts after incubation with wear particles was investigated. Moreover, differences between the abrasive wear of several stem materials and standard bone cement as well as reference particles were analysed.

When the synthesis of procollagen type 1 (CICP) is negatively affected, the de novo synthesis of type 1 collagen is considerably inhibited. Thereby, there are no significant differences between the various particle types according to Yao et al (21). In consequence, in the presence of abrasive wear particles the osteoblast-dependent matrix assembly is affected adversely and, therefore contributes to osteolysis. The second property of osteolysis is characterised by active matrix degradation. This process is activated by special proteinases (e.g. MMP-1) on the one hand and bone resorbing cell types on the other hand. Osteoclasts remove bone tissue and are formed by the fusion of cells of the monocyte-macrophage cell line (32). This differentiation can be induced by different factors, e.g. IL-6 stimulates osteoclast-like multinucleated cell formation from human marrow cells or macrophages (13). Together with MCP-1, IL-8 is chemotactic for lymphocytes, neutrophils and monocytes/macrophages at pico- and nanomolar concentrations. All three chemokines have been identified in the periprosthetic tissue associated with osteolysis (9,33-36).

Human primary osteoblasts release increased levels of IL-6 after treatment with metallic wear particles. This is most impressive after $48 \mathrm{~h}$ of particle incubation and is retained with increasing time. The enhancement was significant for both $\mathrm{Co}-28 \mathrm{Cr}-6 \mathrm{Mo}$, the smooth $\mathrm{Ti}-6 \mathrm{Al}-7 \mathrm{Nb}$ and the $316 \mathrm{~L}$ stems which is analogous at least for cobalt chromium to other findings $(23,37) . \mathrm{ZrO}_{2}$ particles did not influence the IL-6 expression. Therefore, the altered secretion of IL-6 seems not to be related to the particle type used as radio-opaque additive in bone cement. The lower expression of IL-6 after the exposure with higher particle concentrations may result from lower cell amounts caused by higher apoptotic rates. Especially particles from the Co-28Cr-6Mo stems compromised the viability of osteoblasts. Interestingly, there are no differences between the expression rates of the analysed cytokines and the surface finishing of the hip stems examined.

The expression of MCP-1 is considerably reduced after contact with wear particles, although osteoblasts are clearly able to express this cytokine. This is detectable after 48 and $96 \mathrm{~h}$ and significant for the Co-28Cr-6Mo, the smooth Ti-6Al-7Nb and the $316 \mathrm{~L}$ stems. Fritz et al (38) showed in bone marrow derived primary osteoblasts an early stress response with elevated levels of MCP-1 mRNA after 2 and $6 \mathrm{~h}$ and a decline after $12 \mathrm{~h}$. Due to the more chronic character of abrasive wear, our experimental set-up focused on later time points. In the context of macrophage/monocyte activation it is well known that they become competent to perform certain functions in dependence of specific signals. MCP-1 not only attracts monocytes but may also cause cellular activation for specific functions in host defence (39). With respect to osteoblasts, MCP-1 seems not related to osteoclast differentiation by attraction of macrophages/monocytes. Maybe in combination with other cytokines (maybe IL-6 or IL-8) MCP-1 could be relevant for particle induced inflammation.

The IL-8 secretion is increased by osteoblasts after particle treatment. This was significant for Co-28Cr-6Mo stems and for the 316L as well as Ti-6Al-7Nb stems. Interestingly, the enhanced cytokine expression did not remain after longer incubation times. The decline of expression levels was also measured by other groups in vivo (40) and in vitro (38). Hence, by triggering IL-8 osteoblasts may attract osteoclasts and contribute to their migration into the periprosthetic tissue. However, the relatively higher expression levels of IL-8 compared to MCP-1 have also been detected by Fritz et al (38).

VEGF is an indicator of several inflammatory conditions and a key regulator of physiological and pathological angiogenesis (17). Our results show that osteoblasts express VEGF. The release of this cytokine was at least for the lower 
concentration $(0.01 \mathrm{mg} / \mathrm{ml})$ significantly stimulated and after $96 \mathrm{~h}$ further enriched in the particle and reference group. By an increased content in the periprosthetic area the cytokine may attract monocytes and macrophages $(17,41)$. Furthermore, within areas of elevated VEGF concentration enhanced blood vessel growth/angiogenesis can be observed. In the context of pathological angiogenesis the higher vascularisation of inflammatory areas and the vascularisation of tumours (42) for their supply may be mentioned. The secretion of VEGF from osteoblasts treated with different abrasive wear particles suggests that wear debris may induce tumourigenesis in the periprosthetic region. In summary, by expressing increased levels of IL-6, IL-8 and VEGF osteoblasts seem to participate in osteoclast differentiation. Remarkable differences between smooth and rough stems could not be assessed.

The relatively lower expression of IL-6, IL-8 and VEGF after the exposure with higher particle concentrations (primarily CoCr-derived particles) may result from lower cell amounts caused by higher apoptotic rates. In order to compensate the apoptotic rates of particle-treated cells and, therefore reduced cell amounts, all data were referred to the protein content of the cell cultures. However, osteblasts are matrix-secreting cells i.e. besides cell embedded proteins also extracellular matrix proteins were quantified, which results in measuring higher protein concentrations. Furthermore, the protein amount was quantified after $96 \mathrm{~h}$ of incubation but also used for quantification of the $48 \mathrm{~h}$ data. This could result in false higher protein content, which is not precisely proportional to the cell amount.

The results revealed distinct effects on the cytokine release of human osteoblasts towards particulate debris. The cytokineinduced differentiation of osteoclasts for matrix degradation could lead to enhanced degeneration of bone matrix. In addition, by the reduced synthesis of the extracellular matrix protein type 1 collagen, the regeneration of the bone matrix is further inhibited. Moreover, the increased expression of MMP-1 after particle contact would compromise matrix rebuilding and regeneration. The in vitro experiments of this study using particles reveal a release of MMP-1 in osteoblast cultures. Therefore, by the secretion of degradative enzymes, osteoblasts may actively contribute to matrix weakening.

Among the hip stem-derived particles Co-28Cr-6Mo induces the strongest cell reactions. This observation can also be obtained for the type 1 collagen synthesis and apoptotic rates in osteoblast cultures in comparison to other authors $(21,25,43)$. The least aggressive stem-derived particle type seems to be $316 \mathrm{~L}$. Among the reference particles $\mathrm{ZrO}_{2}$ showed slight reactions, although collagen synthesis (CICP) and degradation (MMP-1) were also affected. Thus, it can be assumed that mostly the content of metal particles in the wear debris is the most influencing variable in the culture experiments. All particle types tested, showed a similar size distribution (27) to those found in retrieval studies $(44,45)$. For in vitro tests the size of the particles used should be ensured, since osteoblasts are capable of phagocytosis (44). For example, treatment of an osteoblast culture with particles from rough Ti-6Al-7 $\mathrm{Nb}$ stems shows accumulation of the particles around the nucleus (Fig. 1).

The present study confirms that wear particles can alter the metabolism of human primary osteoblasts. In particular, metallic particles in the wear debris of cemented hip endoprostheses can compromise the vitality and activity of bone cells and bone matrix. In consequence, this may lead to a reduction of implant integration strength (46). Osteoblasts are rather responsible for bone formation, but can indirectly participate in bone degeneration by changing cell-viability and expression of specific chemokines as well as directly by the secretion of pre-osteolytic mediators and specific proteinases. Therefore, in total joint arthroplasty high releases of metallic particles should be avoided in order to reduce adverse cellular reaction and consecutive periprosthetic osteolysis.

\section{Acknowledgements}

We thank Mrs. Susanne Finze for statistical analysis.

\section{References}

1. Purdue PE, Koulouvaris P, Nestor BJ and Sculco TP: The central role of wear debris in periprosthetic osteolysis. HSS J 2: 102-113, 2006.

2. Hallab NJ and Jacobs JJ: Biologic effects of implant debris. Bull NYU Hosp Jt Dis 67: 182-188, 2009.

3. Blaine TA, Rosier RN, Puzas JE, Looney RJ, Reynolds PR, Reynolds SD and O'Keefe RJ: Increased levels of tumor necrosis factor-alpha and interleukin-6 protein and messenger RNA in human peripheral blood monocytes due to titanium particles. J Bone Joint Surg Am 78: 1181-1192, 1996.

4. Chen FS, Scher DM, Clancy RM, Vera-Yu A and Di Cesare PE: In vitro and in vivo activation of polymorphonuclear leukocytes in response to particulate debris. J Biomed Mater Res 48: 904-912, 1999.

5. Dean DD, Schwartz Z, Liu Y, Blanchard CR, Agrawal CM, Mabrey JD, Sylvia VL, Lohmann CH and Boyan BD: The effect of ultra-high molecular weight polyethylene wear debris on MG63 osteosarcoma cells in vitro. J Bone Joint Surg Am 81: 452-461, 1999.

6. Frokjaer J, Deleuran B, Lind M, Overgaard S, Soballe K and Bunger C: Polyethylene particles stimulate monocyte chemotactic and activating factor production in synovial mononuclear cells in vivo. An immunohistochemical study in rabbits. Acta Orthop Scand 66: 303-307, 1995.

7. Goodman SB and Ma T: Cellular chemotaxis induced by wear particles from joint replacements. Biomaterials 31: 5045-5050, 2010.

8. Glant TT, Jacobs JJ, Molnar G, Shanbhag AS, Valyon M and Galante JO: Bone resorption activity of particulate-stimulated macrophages. J Bone Miner Res 8: 1071-1079, 1993.

9. Goppelt-Struebe M and Stroebel M: Synergistic induction of monocyte chemoattractant protein-1 (MCP-1) by platelet-derived growth factor and interleukin-1. FEBS Lett 374: 375-378, 1995.

10. Horowitz SM and Gonzales JB: Inflammatory response to implant particulates in a macrophage/osteoblast coculture model. Calcif Tissue Int 59: 392-396, 1996.

11. Ishiguro N, Kojima T, Ito T, Saga S, Anma H, Kurokonchi K, Iwahori $\mathrm{Y}$, Iwase $\mathrm{T}$ and Iwata $\mathrm{H}$ : Macrophage activation and migration in interface tissue around loosening total hip arthroplasty components. J Biomed Mater Res 35: 399-406, 1997.

12. Kadoya Y, Revell PA, Al-Saffar N, Kobayashi A, Scott G and Freeman MA: Bone formation and bone resorption in failed total joint arthroplasties: histomorphometric analysis with histochemical and immunohistochemical technique. J Orthop Res 14: 473-482, 1996.

13. Kurihara N, Bertolini D, Suda T, Akiyama Y and Roodman GD: IL-6 stimulates osteoclast-like multinucleated cell formation in long term human marrow cultures by inducing IL-1 release. J Immunol 144: 4226-4230, 1990.

14. Kiriakidis S, Andreakos E, Monaco C, Foxwell B, Feldmann M and Paleolog E: VEGF expression in human macrophages is NF-kappaB-dependent: studies using adenoviruses expressing the endogenous NF-kappaB inhibitor IkappaBalpha and a kinasedefective form of the IkappaB kinase 2. J Cell Sci 116: 665-674, 2003.

15. Holmes K, Roberts OL, Thomas AM and Cross MJ: Vascular endothelial growth factor receptor-2: structure, function, intracellular signalling and therapeutic inhibition. Cell Signal 19: 2003-2012, 2007. 
16. Klagsbrun M and D'Amore PA: Regulators of angiogenesis. Ann Rev Physiol 53: 217-239, 1991.

17. Zittermann SI and Issekutz AC: Endothelial growth factors VEGF and bFGF differentially enhance monocyte and neutrophi recruitment to inflammation. J Leukoc Biol 80: 247-257, 2006.

18. Wu WS, Wang FS, Yang KD, Huang CC and Kuo YR: Dexamethasone induction of keloid regression through effective suppression of VEGF expression and keloid fibroblast proliferation. J Invest Dermatol 126: 1264-1271, 2006.

19. Vidovszky TJ, Cabanela ME, Rock MG, Berry DJ, Morrey BF and Bolander ME: Histologic and biochemical differences between osteolytic and nonosteolytic membranes around femoral components of an uncemented total hip arthroplasty. J Arthroplasty 13 : 320-330, 1998

20. Vermes C, Chandrasekaran R, Jacobs JJ, Galante JO, Roebuck KA and Glant TT: The effects of particulate wear debris, cytokines, and growth factors on the functions of MG-63 osteoblasts. J Bone Joint Surg Am 83-A: 201-211, 2001.

21. Yao J, Cs-Szabo G, Jacobs JJ, Kuettner KE and Glant TT: Suppression of osteoblast function by titanium particles. J Bone Joint Surg Am 79: 107-112, 1997.

22. Goodman S, Aspenberg P, Song Y, Knoblich G, Huie P, Regula D and Lidgren L: Tissue ingrowth and differentiation in the boneharvest chamber in the presence of cobalt-chromium-alloy and high-density-polyethylene particles. J Bone Joint Surg Am 77: 1025-1035, 1995.

23. Anissian L, Stark A, Dahlstrand H, Granberg B, Good V and Bucht E: Cobalt ions influence proliferation and function of human osteoblast-like cells. Acta Orthop Scand 73: 369-374, 2002.

24. Fritz EA, Glant TT, Vermes C, Jacobs JJ and Roebuck KA: Chemokine gene activation in human bone marrow-derived osteoblasts following exposure to particulate wear debris. J Biomed Mater Res A 77: 192-201, 2006.

25. Goodman SB, Ma T, Chiu R, Ramachandran R and Smith RL: Effects of orthopaedic wear particles on osteoprogenitor cells. Biomaterials 27: 6096-6101, 2006.

26. Bader R,SteinhauserE,Holzwarth U, Schmitt Mand MittelmeierW: A novel test method for evaluation of the abrasive wear behaviour of total hip stems at the interface between implant surface and bone cement. Proc Inst Mech Eng H 218: 223-230, 2004.

27. Lenz R, Mittelmeier W, Hansmann D, Brem R, Diehl P, Fritsche A and Bader R: Response of human osteoblasts exposed to wear particles generated at the interface of total hip stems and bone cement. J Biomed Mater Res A 89: 370-378, 2008.

28. Santavirta S, Xu JW, Hietanen J, Ceponis A, Sorsa T, Kontio R and Konttinen YT: Activation of periprosthetic connective tissue in aseptic loosening of total hip replacements. Clin Orthop Relat Res 352: 16-24, 1998.

29. Purdue PE, Koulouvaris P, Potter HG, Nestor BJ and Sculco TP The cellular and molecular biology of periprosthetic osteolysis. Clin Orthop Relat Res 454: 251-261, 2007.

30. Gallo J, Kaminek P, Ticha V, Rihakova P and Ditmar R: Particle disease. A comprehensive theory of periprosthetic osteolysis: a review. Biomed Pap Med Fac Univ Palacky Olomouc Czech Repub 146: 21-28, 2002.
31. Ingham $\mathrm{E}$ and Fisher J: Biological reactions to wear debris in total joint replacement. Proc Inst Mech Eng H 214: 21-37, 2000.

32. Netter FH: The CIBA Collection of Medical Illustration Musculoskeletal System: Part I: Anatomy, Physiology and Metabolic Disorders. Vol. 8, CIBA Corporation-Geigy, Summit, p169, 1987.

33. Lakshminarayanan V, Beno DW, Costa RH and Roebuck KA Differential regulation of interleukin-8 and intercellular adhesion molecule- 1 by $\mathrm{H}_{2} \mathrm{O}_{2}$ and tumor necrosis factor-alpha in endothelial and epithelial cells. J Biol Chem 272: 32910-32918, 1997.

34. Williams RP and McQueen DA: A histopathologic study of late aseptic loosening of cemented total hip prostheses. Clin Orthop Relat Res 275: 174-179, 1992.

35. Chiba J, Rubash HE, Kim KJ and Iwaki Y: The characterization of cytokines in the interface tissue obtained from failed cementless total hip arthroplasty with and without femoral osteolysis. Clin Orthop Relat Res 300: 304-312, 1994.

36. Murray DW and Rushton N: Mediators of bone resorption around implants. Clin Orthop Relat Res 281: 295-304, 1992.

37. Wilke A, Bartsch I, Kratz M, Jones D and Endres S: Cytokine profile of a human bone marrow cell culture under the influence of UHMW-PE wear particles. Biomed Tech (Berl) 50: 330-336, 2005 (In German).

38. Fritz EA, Glant TT, Vermes C, Jacobs JJ and Roebuck KA: Titanium particles induce the immediate early stress responsive chemokines IL-8 and MCP-1 in osteoblasts. J Orthop Res 20: 490-498, 2002.

39. Leonard EJ and Yoshimura T: Human monocyte chemoattractant protein-1 (MCP-1). Immunol Today 11: 97-101, 1990.

40. Thijs LG and Hack CE: Time course of cytokine levels in sepsis. Intensive Care Med 21 (Suppl 2): S258-S263, 1995.

41. Barleon B, Sozzani S, Zhou D, Weich HA, Mantovani A and Marme D: Migration of human monocytes in response to vascular endothelial growth factor (VEGF) is mediated via the VEGF receptor flt-1. Blood 87: 3336-3343, 1996.

42. Pasieka Z, Stepien H, Komorowski J, Kolomecki K and Kuzdak K: Evaluation of the levels of bFGF, VEGF, sICAM-1, and sVCAM-1 in serum of patients with thyroid cancer. Recent Results Cancer Res 162: 189-194, 2003.

43. Allen MJ, Myer BJ, Millett PJ and Rushton N: The effects of particulate cobalt, chromium and cobalt-chromium alloy on human osteoblast-like cells in vitro. J Bone Joint Surg Br 79: 475-482, 1997.

44. Brandwood A, Noble KR and Schindhelm K: Phagocytosis of carbon particles by macrophages in vitro. Biomaterials 13: 646-648, 1992.

45. Pioletti DP, Takei H, Kwon SY, Wood D and Sung KL: The cytotoxic effect of titanium particles phagocytosed by osteoblasts. J Biomed Mater Res 46: 399-407, 1999.

46. Choi MG, Koh HS, Kluess D, et al: Effects of titanium particle size on osteoblast functions in vitro and in vivo. Proc Natl Acad Sci USA 102: 4578-4583, 2005. 